\title{
Successful liver and kidneys transplant following aortic dissection and subclavian artery rupture: A case report
}

Milad Gholizadeh Mesgarha ${ }^{1}$, Sam Zeraatian Nejad Davani ${ }^{2}$, Aisa Talebi ${ }^{3}$, Ali Saberi Shahrbabaki $^{3}$, Arash Pour Mohammad ${ }^{1}$, and Yazdan Shafikhani ${ }^{1}$

${ }^{1}$ Iran University of Medical Sciences

${ }^{2}$ Hazrat-e Rasool General Hospital

${ }^{3}$ Shahid Beheshti University of Medical Sciences School of Medicine

March 5, 2022

\begin{abstract}
Despite the increasing number of liver and kidney transplants, the number of awaiting patients for a proper donor is still exceeding. Therefore, the preservation of donor's organs is critically advocated. Herein, we presented a successful liver and kidneys transplant from a brain dead donor who was found preoperatively to have simultaneous aortic dissection and intramural hematoma, and additionally developed left subclavian artery dissection and perforation following sternotomy. This case experience highlights the key role of cardiac surgeons to preserve visceral organs by rapid repair of aorta and its branches perforation site and dissection which culminate in lifesaving organ donation.
\end{abstract}

\section{Hosted file}

Transplant Manuscript.docx available at https://authorea.com/users/447460/articles/558741successful-liver-and-kidneys-transplant-following-aortic-dissection-and-subclavianartery-rupture-a-case-report

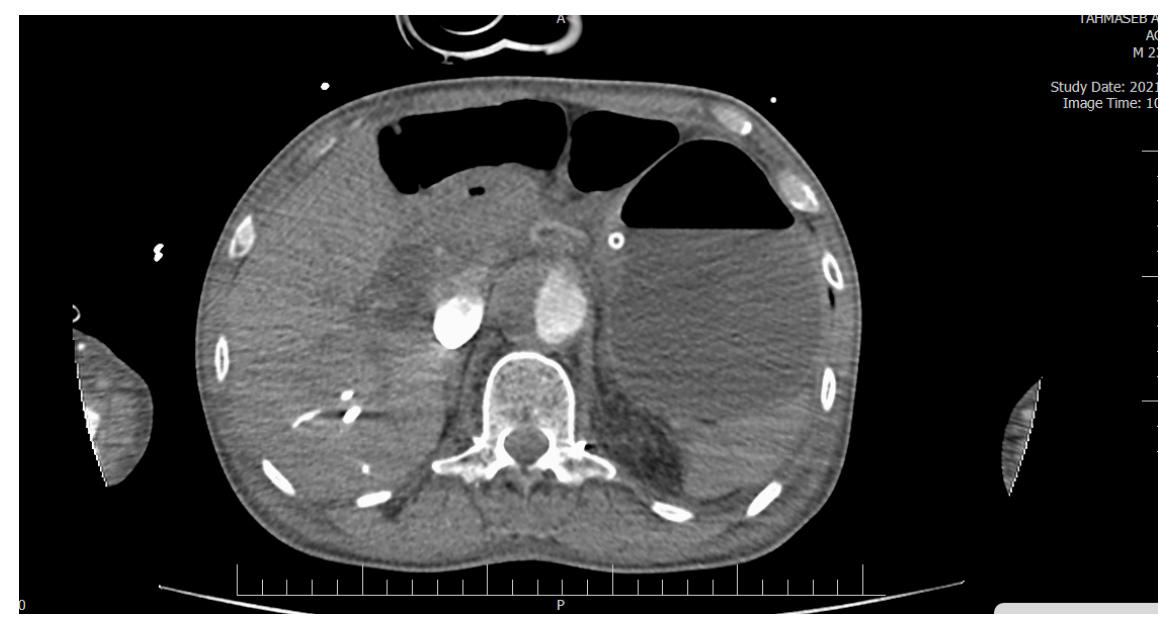



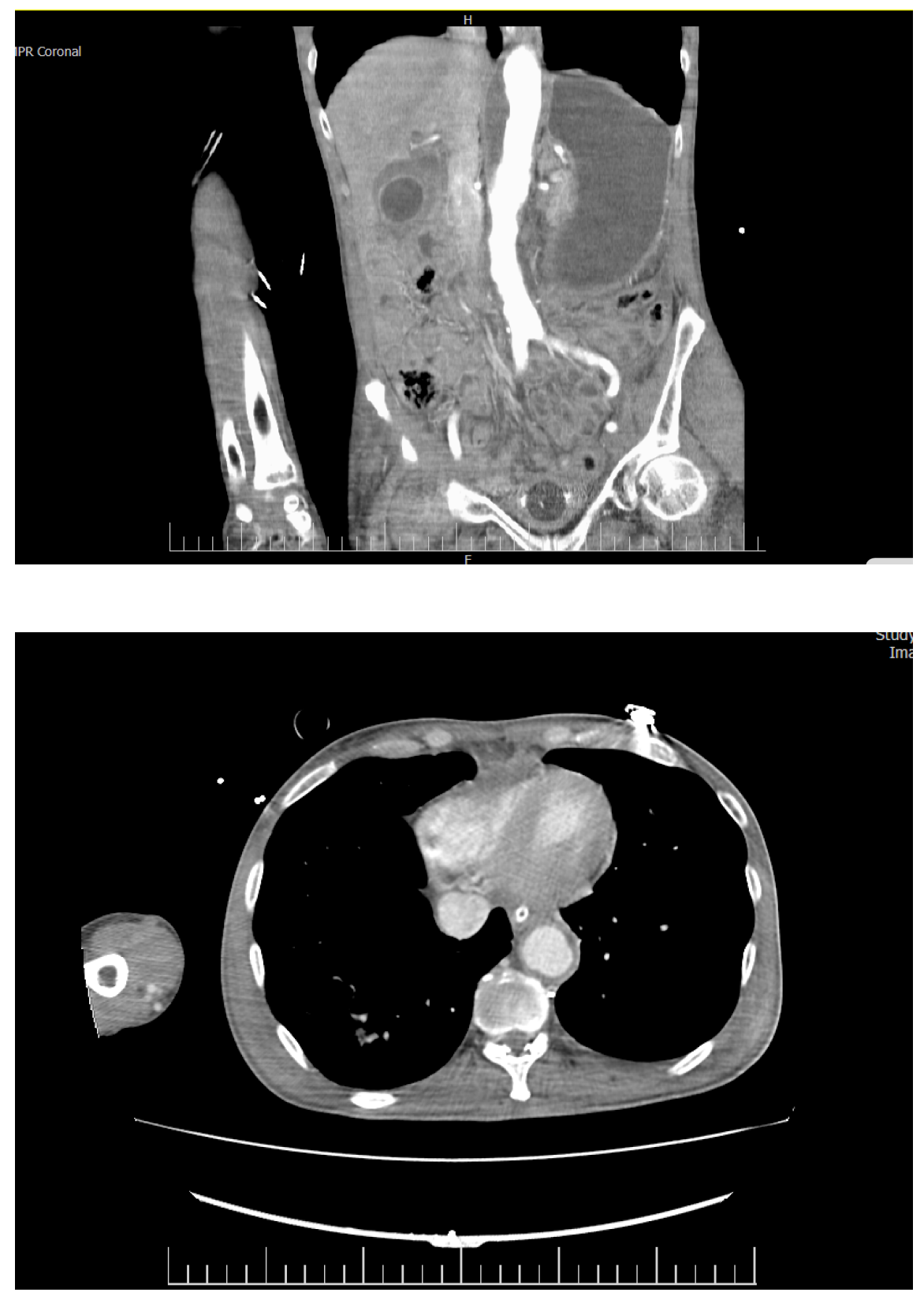

\section{Hosted file}

Video-1.mp4 available at https://authorea.com/users/447460/articles/558741-successful-liverand-kidneys-transplant-following-aortic-dissection-and-subclavian-artery-rupture-a-casereport 